\title{
RELAÇÃO DOS ÍNDICES DE ACIDENTES DO TRABALHO NO ESPÍRITO SANTO E BRASIL DE 2007 A 2017 NA CONSTRUÇÃO DE EDIFÍCIOS
}

\section{LIST OF WORK ACCIDENT INDEXES IN THE ESPÍRITO SANTO AND BRAZIL 2007-2017 IN BUILDING BUILDINGS}

\author{
Wanderson Lyrio Bermudes ${ }^{1 凶}$, Kleidismar Ramos Fontana ${ }^{2}$ \\ Instituto Federal do Espirito Santo (IFES), Vitória, Espirito Santo, Brasil \\ ${ }^{2}$ Universidade Cândido Mendes (UCAM), Vitória, Espirito Santo, Brasil \\ 凶wanderson.bermudes@hotmail.com
}

Recebido: 14 agosto 2019 / Aceito: 04 novembro 2019/ Publicado: 17 dezembro 2019

\begin{abstract}
This research presents statistical data on occupational accidents in building construction activities in the State of Espírito Santo and Brazil to assess the evolution of these indicators over the period analyzed. The research used data from occupational accidents available in the Statistical Yearbook of Accidents at Work of Social Security for the periods from 2007 to 2017 and bibliographic study. In the surveyed period, there were 197,312 occupational accidents in Brazil (typical, commute or occupational disease) in building construction activities. The risks originate from machinery and equipment, manual and height work, as well as indoor and outdoor environmental conditions. As a result, this research showed that the state of Espírito Santo has an accident record amount that contributed $5.48 \%$ of the total accidents in Brazil in 2008 and presented in 2017 the rate of $2.19 \%$, indicating a decrease in this participation. When analyzing the incidence rate of accidents typical of this occurrence, the state has a higher indicator than the national average during the surveyed period, with a downward trend. With regard to occupational disease, there is a reduction of this incidence in the research interval. These reductions may be justified by the application of control measures and government actions. There is an increase in the rates of commuting accidents in this segment, which to reduce them requires the adoption of public policies that are beyond the company's management capacity.
\end{abstract}

Keywords: Construction. Job. Accident. Indicators.
RESUMO. Esta pesquisa apresenta os dados estatísticos de acidentes do trabalho nas atividades de construção de edifício no Estado do Espírito Santo e no Brasil para avaliar a evolução desses indicadores no período analisado. A pesquisa utilizou dados dos acidentes de trabalho disponíveis no Anuário Estatístico de Acidentes do Trabalho da Previdência Social referente aos períodos de 2007 a 2017 e estudo bibliográfico. No intervalo pesquisado, ocorreram no Brasil, 197.312, acidentes do trabalho (típico, trajeto ou doença do trabalho) nas atividades de construção de edifício. Os riscos são originados das máquinas e equipamentos, trabalho braçal e em altura, além das condições do ambiente interno e externo. Como resultado essa pesquisa demonstrou que o Estado do Espírito Santo, possui uma quantidade de registro de acidente que contribuiu em $5,48 \%$ do total de acidentes no Brasil em 2008 e apresentou em 2017 o índice de $2,19 \%$, indicando queda dessa participação. Quando analisado a Taxa de Incidência de acidente de típico dessa ocorrência o Estado possui indicador maior que a média nacional durante o período pesquisado, com tendência de redução. No que se refere a doença do trabalho, nota-se uma redução dessa incidência no intervalo da pesquisa. Reduções essas que podem ser justificadas pela aplicação de medidas de controle e ações governamentais. Registra-se o acréscimo dos índices dos acidentes de trajeto nesse segmento, que para sua redução é necessário a adoção de políticas públicas que fogem da capacidade de gestão da empresa.

Palavras-Chave: Construção. Trabalho. Acidente. Indicadores. 


\section{INTRODUÇÃO}

No Brasil, as atividades de construção civil destacam-se por contribuir com a geração de empregos, e em 2017 obtiveram o total 12,5 milhões de ocupações formais, informais, diretos e indiretos, sendo o setor que mais emprega no país, e contribuiu com $6,5 \%$ do Produto Interno Bruto - PIB nesse mesmo ano (CÂMARA BRASILEIRA DA INDUSTRIA DA CONSTRUÇÃO - CBIC, 2017). Nos últimos anos com os eventos da Copa do Mundo em 2014 e as Olimpíadas de 2016 reforçaram ainda mais essa importância desse segmento (BRASIL, 2016).

Dentre as diversas atividades de construção civil, esta pesquisa destaca a construção de edifício que possui as seguintes etapas principais de organização: escolha do terreno, projeto de arquitetura, orçamento da obra, planejamento, infraestrutura ou fundações, alvenaria, cobertura, instalações, acabamentos e revestimentos (ASSUMPÇÃO; LIMA JR, 1996).

A construção de edifícios empregou aproximadamente 1.1000.000 trabalhadores formais no país conforme dados do Ministério do Trabalho - MT em 2016 (ANUÁRIO ESTATÍSTICO DE ACIDENTES DO TRABALHO - AEAT, 2017), e vem ao longo dos anos contribuindo significativamente para o aumento da qualidade de vida da população, ao proporcionar habitação em condições adequadas, gerando renda e comercialização de insumos (FREITAS; NISHIMURA; ALMEIDA, 2018).

Apesar da grande importância do segmento, a construção de edifício no Brasil, registrou de 2007 a 2017 um total 197.312 acidentes de trabalho (acidentes típicos, doenças do trabalho ou trajetos) e 1335 mortes (AEAT, 2017) ocasionados pelos mais variados tipos de riscos ocupacionais (SANTOS; SOUZA; ARAÚJO, 2018).

Maia (2014) apresentou, em sua pesquisa, que os riscos na construção de edifícios ocorrem em todas as etapas construtivas e com os mais variados agentes como ruído, calor, vibração, poeira, postura inadequada, movimentação manual de carga, possibilidade de quedas, projeções de materiais entre outros.

Essa quantidade de riscos ocupacionais, na indústria da construção civil, não é apenas uma característica do Brasil, mas alcança todos os países, apesar de ocorrer a implementação 


\section{REVISTA LATINO-AMERICANA DE INOVAÇÃO E \\ ENGENHARIA DE PRODUÇÃO}

de vários tipos de medidas de segurança para reduzir a probabilidade de acidentes nos locais (LI, 2017).

Nesse contexto podemos destacar a indústria da construção nos Estados Unidos da América - EUA e na União Europeia que tem elevados números de acidentes de trabalho. Nos EUA, a indústria da construção é o terceiro setor mais perigoso de se trabalhar. Tendo em $2015,21,4 \%$ todas as fatalidades de trabalhadores na indústria privada. Na Europa, mais de um em cada cinco (20,9\%) acidentes fatais no trabalho em 2014 ocorreram no setor da construção, e ainda possui uma das maiores taxas de incidência de lesões (ANDERSEN et al., 2018).

Diante desse cenário essa pesquisa tem por objetivo apresentar dados estatísticos de acidentes de trabalho na construção de edifício no Espirito Santo em comparação com a média do Brasil de forma a avaliar a evolução desses indicadores no período de 2007 a 2017 e analisar o motivo dessas variações, de forma a contribuir com a elaboração ou aprimoramento de programas ou políticas de prevenção de riscos.

\section{METÓDO}

O método de pesquisa considerou a revisão bibliográfica, que incluiu referências nacionais e internacionais, com caráter descritivo, com propósito exploratório, de natureza qualitativa e quantitativa, que indicavam cenários de riscos, números e indicadores de acidentes de trabalho.

Nesse contexto os acidentes de trabalho são aqueles definidos conforme o Artigo $19^{\circ}$ da Lei n. ${ }^{\circ} 8.213$, de 24 de Julho 1991:

[...] acidente do trabalho é todo aquele que ocorre pelo exercício do trabalho, a serviço da empresa, provocando lesão corporal ou perturbação funcional que cause a morte ou a redução, permanente ou temporária, da capacidade para o trabalho. [...]" (AEAT, 2017; BRASIL, 1991).

Equiparam-se aos acidentes de trabalho as doenças do trabalho, aquelas produzidas ou desencadeadas pelo exercício do trabalho peculiar a determinado ramo de atividade, ou aquelas adquiridas ou desencadeadas em função de condições especiais em que o trabalho é realizado e com ele se relacione diretamente; e os acidentes ocorrido no deslocamento do 


\section{REVISTA LATINO-AMERICANA DE INOVAÇÃO E \\ ENGENHARIA DE PRODUÇÃO}

trabalhador de casa para o trabalho e vice-versa, denominado de trajeto (AEAT, 2017; BRASIL, 1991).

Nessa pesquisa os dados de acidente foram separados conforme os seguintes conceitos: típicos (são os acidentes decorrentes da característica da atividade profissional desempenhada pelo segurado acidentado), doenças do trabalho e trajeto em que ocorreram emissão da Comunicação do Acidente de Trabalho - CAT.

Os indicadores e números de acidentes de trabalho foram obtidos por meio da base de dados histórico de acidentes de trabalho do Ministério da Previdência Social - MPS, AEAT INFOLOG, selecionado como acidentes e os indicadores na mesma base de dados.

Os dados foram obtidos na categoria: Construção de edifício (Código 4120), de acordo com a Classificação Nacional de Atividade Econômica - CNAE disponibilizado pelo AEAT (2017) e apresentados em números absolutos de ocorrência, incidência de acidentes típicos e doenças do trabalho para grupo de mil trabalhadores, números de vínculos empregatícios e quantitativo de acidentes de trajeto.

Essa relação de quantitativos de acidentes relacionados com o número de vínculos empregatícios no segmento é denominado como Taxa de Incidência - TI aplicado para acidentes típicos e doença do trabalho, valor esse também disponível no AEAT (2017) e calculado, conforme descreve a Equação 1:

$$
\mathrm{TI}=(\mathrm{NAT} \div \mathrm{NMV}) \times 100
$$

Onde:

$\mathrm{TI}=$ Taxa de incidência;

NAT $=$ Número de novos casos de acidentes do trabalho (típicos ou doenças do trabalho) registrados com CAT;

$\mathrm{NMV}=$ Número médio anual de vínculos 


\section{RESULTADOS}

A indústria da construção civil é reconhecida por ser um ambiente complexo, competitivo, e estrategicamente importante pela capacidade de construir infraestrutura e para o desenvolvimento econômico regional e global (AMARILLA; IAROZINSKI NETO, 2018).

Apesar da grande relevância desse segmento para o país, a construção civil é um ramo de atividade que deixa muito a desejar, quando se trata de saúde e segurança dos trabalhadores. Pesquisas apontam precariedade em relação à prevenção de risco neste setor, resultando em prejuízos à saúde humana, assim como perdas financeiras às próprias instituições, governo e sociedade (BERMUDES; BARROS, 2016; REIS; GUIMARÃES, 2017).

Diante esse cenário e a partir das informações disponibilizadas no AEAT, em consulta pública, foram apresentados dados de estatística de acidente de trabalho envolvendo o Estado do Espírito Santo - ES e o Brasil, nas atividades de construção de edifício no período de 2007 a 2017.

Conforme dados do AEAT a TABELA 1 apresenta os dados dos registros de acidentes do trabalho típico no Estado do Espírito Santo e sua contribuição percentual com os registrados em todo país

TABELA 1 - NÚMEROS DE ACIDENTE DE TRABALHO NA CONSTRUÇÃO DE EDIFÍCIOS DO ESTADO DO ESPÍRITO SANTO E DO BRASIL DE 2007 A 2017

\begin{tabular}{c|c|c|c}
\hline \multirow{2}{*}{ Ano } & \multicolumn{2}{c}{ Local } & \multicolumn{2}{c}{$\begin{array}{c}\text { Percentual de acidentes típicos no Espírito Santo em } \\
\text { comparação com o Brasil na construção de edifícios (\%) }\end{array}$} \\
\cline { 2 - 3 } 2007 & 8.968 & 702 & $5,30 \%$ \\
\hline 2008 & 11.167 & 951 & $5,73 \%$ \\
\hline 2009 & 11.386 & 696 & $4,13 \%$ \\
\hline 2010 & 12.453 & 626 & $3,74 \%$ \\
\hline 2011 & 13.433 & 626 & $3,44 \%$ \\
\hline 2012 & 13.439 & 626 & $3,53 \%$ \\
\hline 2013 & 12.907 & 459 & $2,67 \%$ \\
\hline 2014 & 12.643 & 408 & $2,55 \%$ \\
\hline 2015 & 10.163 & 239 & $2,35 \%$ \\
\hline 2016 & 7.784 & 135 & $1,73 \%$ \\
\hline 2017 & 5.978 & 131 & $2,19 \%$ \\
\hline
\end{tabular}

FONTE: AEAT (2017)

Em outra perspectiva de análise a TABELA 2 apresenta o quantitativo de vínculo empregatício (CNAE 4210) no estado do ES e o percentual em relação ao Brasil de 2009 a 2016, conforme disponibilizado pelo AEAT (2017). 
TABELA 2 - QUANTITATIVO E O PERCENTUAL DE MÃO DE OBRA DO ESPÍRITO SANTO NA ATIVIDADE DE CONSTRUÇÃO DE EDIFÍCIO E A COMPARAÇÃO COM O BRASIL DE 2009 A 2016

\begin{tabular}{c|c|c|c|}
\hline \multirow{2}{*}{ Ano } & \multicolumn{2}{|c|}{ Local } & \multirow{2}{*}{$\begin{array}{c}\text { Percentual de vínculos empregatícios no Espírito } \\
\text { Santo em comparação com o Brasil (\%) }\end{array}$} \\
\cline { 2 - 3 } & Brasil & Espírito Santo & $3,08 \%$ \\
\hline 2009 & 865.962 & 26.650 & $2,72 \%$ \\
\hline 2010 & 1.080 .431 & 29.439 & $2,56 \%$ \\
\hline 2011 & 1.248 .019 & 31.931 & $2,51 \%$ \\
\hline 2012 & 1.355 .324 & 33.976 & $2,24 \%$ \\
\hline 2013 & 1.391 .666 & 31.119 & $1,76 \%$ \\
\hline 2014 & 1.126 .791 & 19.826 & $1,57 \%$ \\
\hline 2015 & 1.061 .876 & 16.705 & $1,53 \%$ \\
\hline 2016 & 839.630 & 12.870 & \\
\hline
\end{tabular}

FONTE: AEAT (2017)

Quando analisado a TABELA 1 em conjunto com a TABELA 2 é possível observar que o percentual de acidentes de trabalho típico que o estado do ES contribui é superior ao percentual de vínculo empregatício, nessa atividade, em comparação com o Brasil, no período analisado de 2009 a 2016, o que indica uma maior ocorrência de acidentes típicos no ES em relação a mão de obra disponível. Para corroborar com essa análise faz-se necessário, relacionarmos o número de acidentes típicos com o número médio anual de vínculos empregatícios no período, descrito como TI.

Nesse âmbito a Figura 1 apresenta a TI de acidentes do trabalho típico na construção de edifícios do ES e do Brasil no período disponibilizado de 2007 a 2017 (AEAT, 2017).

\section{FIGURA 1 - TAXA DE INCIDÊNCIA DE ACIDENTES DE TRABALHO TÍPICO NO ESTADO DO ESPÍRITO SANTO E DO BRASIL DE 2007 A 2017}

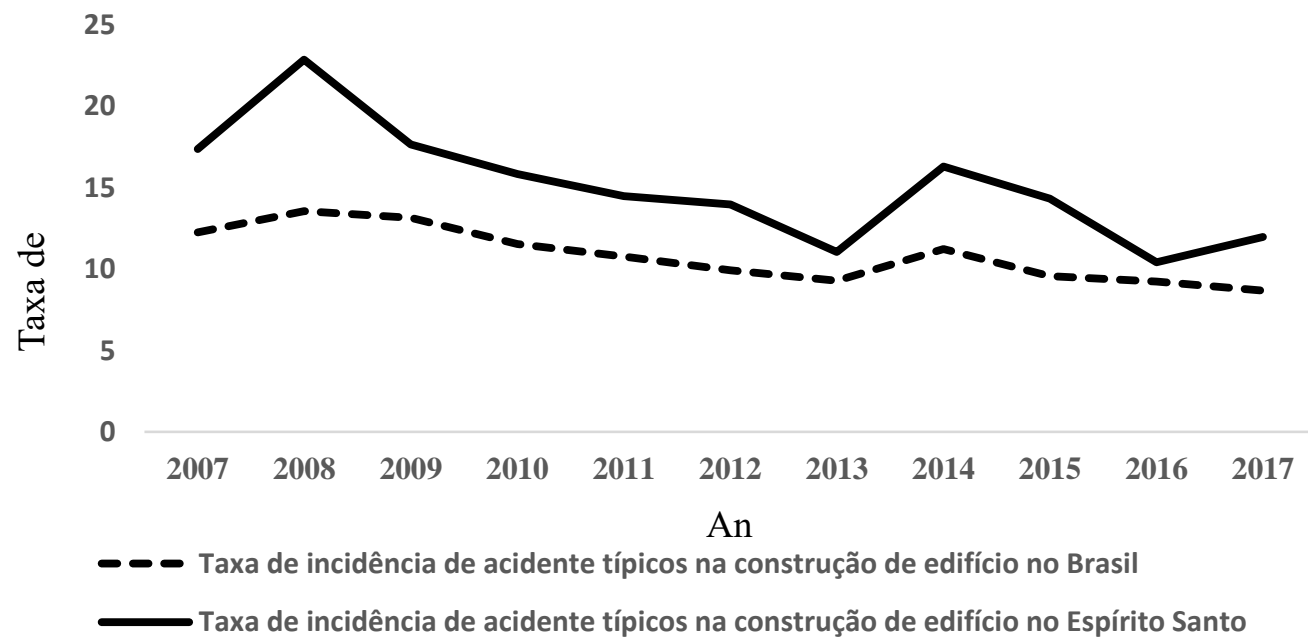

FONTE: AEAT (2017) 


\section{REVISTA LATINO-AMERICANA DE INOVAÇÃO E \\ ENGENHARIA DE PRODUÇÃO}

No que se refere a doença do trabalho a Figura 2 indica uma redução dos índices referentes ao Brasil e do ES, ao longo do período analisado, mas com o estado apresentando uma maior variação nesse item.

FIGURA 2 - TAXA DE INCIDÊNCIA DE DOENÇA DO TRABALHO NO ESTADO DO ESPÍRITO SANTO E DO BRASIL DE 2007 A 2017

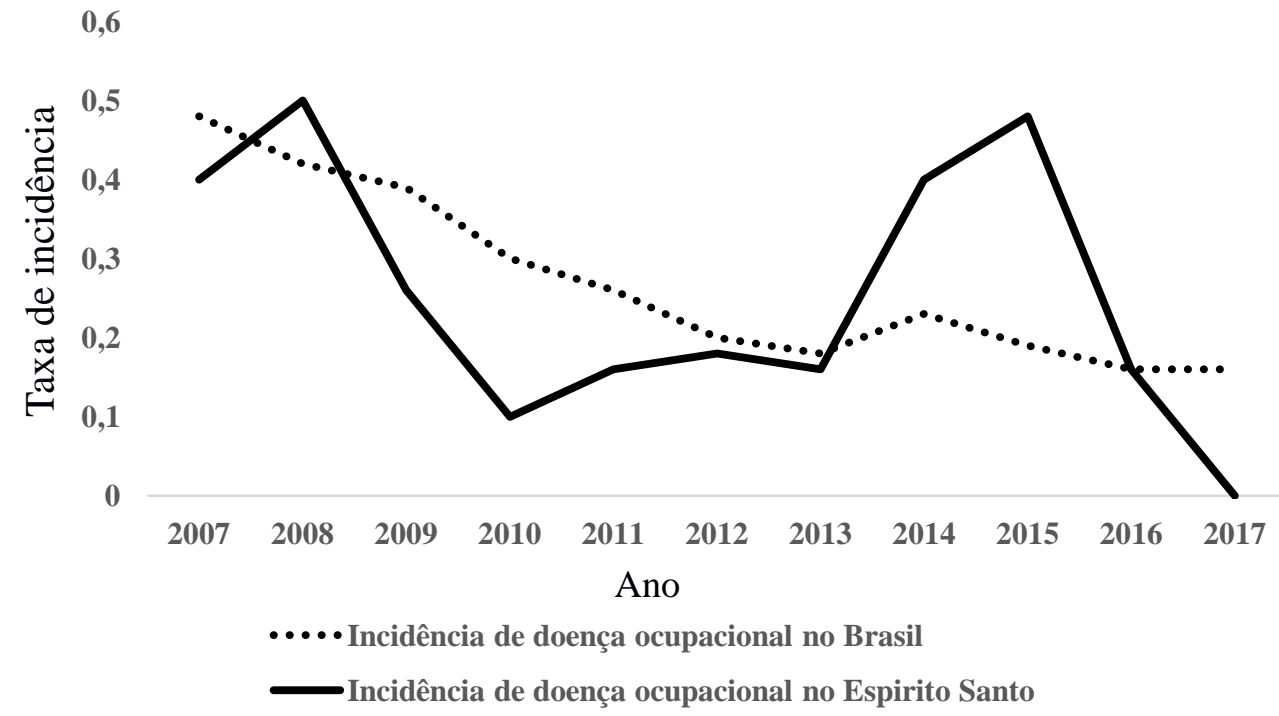

FONTE: AEAT (2017)

TABELA 3 - PERCENTUAL DE ACIDENTES DE TRAJETO NAS ATIVIDADES DE CONSTRUÇÃO DE EDIFÍCIOS NO BRASIL E NO ESPÍRITO SANTO DE 2007 A 2017 EM RELAÇÃO AOS DEMAIS TIPOS DE ACIDENTES

\begin{tabular}{ccc}
\hline \multirow{2}{*}{ Ano } & Percentual (\%) de acidentes de trajeto ocorridos na construção de edifícios em relação aos acidentes \\
\cline { 2 - 3 } & Brasicos e doenças ocupacionais & Espírito Santo \\
\hline 2007 & $9,18 \%$ & $5,74 \%$ \\
\hline 2008 & $8,3 \%$ & $4,98 \%$ \\
\hline 2009 & $8,9 \%$ & $11,98 \%$ \\
\hline 2010 & $10,02 \%$ & $8,93 \%$ \\
\hline 2011 & $10,58 \%$ & $13,82 \%$ \\
\hline 2012 & $10,17 \%$ & $10,41 \%$ \\
\hline 2013 & $11,41 \%$ & $11,44 \%$ \\
\hline 2014 & $16,16 \%$ & $12,83 \%$ \\
\hline 2015 & $15,02 \%$ & $14,95 \%$ \\
\hline 2016 & $15,92 \%$ & $18,54 \%$ \\
\hline 2017 & $14,58 \%$ & $14,97 \%$ \\
\hline Média & $11,84 \%$ & $11,69 \%$ \\
\hline
\end{tabular}

FONTE: AEAT (2017)

Rev. Lat.-Am. Inov. Eng. Prod. [Relainep]

Curitiba, Paraná, Brazil v. 7 n. 12 p. $05-192019$

DOI: $10.5380 /$ relainep.v7i12.68508 


\section{REVISTA LATINO-AMERICANA DE INOVAÇÃO E \\ ENGENHARIA DE PRODUÇÃO}

Outro índice de relevância nesse segmento, são os acidentes de trajeto, que tem apresentado aumento gradativo de ocorrência, no segmento de construção de edifício, no Espírito Santo e no Brasil, no período de 2007 a 2017 em relação aos demais tipos de acidentes (TABELA 3).

\section{DISCUSSÃO}

Embora exista mecanismos de prevenção de riscos, os acidentes na construção de edifícios ocorrem e são originados por diversos fatores conforme destacado por Santos, Sousa e Araújo (2018): a negligência na instrução ao trabalhador, falta de conhecimento técnico, atitudes imprudentes e ausência ou negligência na fiscalização.

Zanette et al (2018) e Müller (2018) ratificam o trabalho de Santos, Sousa e Araújo (2018) e destacam também o trabalho braçal, o uso de máquinas e equipamentos sem treinamento, falta de proteção coletiva, ausência do uso de equipamentos de proteção individual, trabalho em altura e as condições do ambiente como outros fatores que contribuem com a ocorrência dos acidentes de trabalho.

Os dados da TABELA 1 (Números de acidente de trabalho na construção de edifícios do Estado do Espírito Santo e do Brasil de 2007 a 2017) indicam como fator de relevância a redução gradativa do percentual da contribuição dos acidentes típicos na construção de edifício pelo estado do Espírito Santo - ES ao país, que apontou o maior valor de 5,73\% no ano de 2008 e em 2016 a menor incidência, chegando ao valor de 1,73\% do total de acidentes no Brasil nesse segmento.

Dados esses que corroboram com Rondon, Nóbrega e Magdaleno (2018), que apresentaram uma tendência de redução ocorrência de acidentes no ES inferior à média nacional durante o período de 2003 a 2014, conforme indica a TABELA 2 (Quantitativo e o percentual de mão de obra do Espírito Santo na atividade de construção de edifício e a comparação com o Brasil de 2009 a 2016) dessa pesquisa.

A análise da Figura 1 (Taxa de incidência de acidentes de trabalho típico no Estado do Espírito Santo e do Brasil de 2007 a 2017) indica que apesar do baixo número de registro de acidentes de trabalho típicos na construção de edifício no Estado do Espírito Santo, quando comparado em termos de incidência ao País, o ES está superior média nacional. Indicando 


\section{REVISTA LATINO-AMERICANA DE INOVAÇÃO E \\ ENGENHARIA DE PRODUÇÃO}

que há maior registro de acidente para cada grupo de 1.000 trabalhadores no ES do que na média brasileira no período analisado.

Em contrapartida, também na observação da Figura 1, registra-se também uma redução gradativa da ocorrência de incidência dos acidentes típicos na construção de edifícios no ES e no Brasil no período estudado. Essa redução melhora a qualidade de vida no trabalho do executante, haja vista que as melhores condições de segurança e saúde proporciona tal percepção (FREITAS et al., 2016).

A apreciação da Figura 2 (Taxa de incidência de doença do trabalho no Estado do Espírito Santo e do Brasil de 2007 a 2017) também exibe uma baixa incidência de doenças do trabalho, em que o maior valor foi de 0,5 registro para cada grupo de 1.000 trabalhadores em 2008, que indica um maior controle desses riscos no segmento em estudo. No ES em 2017 a incidência atingiu o valor de zero.

Essas reduções, apresentadas nas Figuras 1 e 2, podem ser justificadas por uma série de fatores. $\mathrm{Na}$ indústria da construção civil as empresas são obrigadas a adotarem programa de prevenção de risco como o Programa de Condições e Meio Ambiente de Trabalho na Indústria de Construção - PCMAT e Prevenção dos Riscos Ambientais - PPRA que são mecanismos que indicam e controlam os riscos ocupacionais e Programa de Controle Médico de Saúde Ocupacional - PCMSO que auxilia no monitoramento da saúde do trabalhador e pode contribuir na prevenção de doenças do trabalho (BEZERRA; CARVALHO, 2011; ZANETTE et al., 2018) .

Outro fator que pode justificar a redução desses índices, que se destaca a partir de 2010, é a aplicação e fortalecimento de dois mecanismos do governo federal, que são as ações regressivas do Instituto Nacional do Seguro Social - INSS e o novo cálculo de Risco de Acidente de Trabalho - RAT (NININ, 2018; SILVA, 2017; VERGÍNIO, 2018).

As ações regressivas buscam cobrar das empresas ou outrem, valores despendidos com benefícios e serviços concedidos aos segurados acidentados em decorrência do desrespeito às normas de segurança e higiene do trabalho, que diante dessa cobrança, pode estimular a empresa a adotar ações de prevenção de risco (NININ, 2018).

Enquanto o RAT é o adicional pago pelo empregador para um fundo no qual o trabalhador poderá receber em caso de acidentes de trabalho gerados pela exposição aos riscos 


\section{REVISTA LATINO-AMERICANA DE INOVAÇÃO E \\ ENGENHARIA DE PRODUÇÃO}

ambientais, alterado pelo Fator Acidentário previdenciário - FAP, que podem reduzir pela metade ou duplicar essa contribuição, conforme os registros de acidentes ou uso de benefícios financeiros do governo originados devido a casos de acidentes ou doenças relacionadas ao trabalho (SILVA, 2017; VERGÍNIO, 2018).

Pode-se também destacar nessa redução de incidência de acidentes a atualização constante da Norma Regulamentadora - NR 18 (Condições e meio ambiente de trabalho na indústria da construção), nos últimos 40 anos e o surgimento de novas normativas de padronização do trabalho (SILVA; BEMFICA, 2015).

Para Iida (2005) a segurança do trabalho, possui dois objetivos principais: o de preservar a saúde do trabalhador, proporcionando ambientes de trabalho seguros e saudáveis, reduzindo os índices de acidentes e o de garantir que a empresa esteja cumprindo os requisitos legais exigidos.

Para a garantia desses dois objetivos as empresas devem empregar mecanismos de gerenciamento de risco próprios ou terceirizados, que incluem os controles de riscos conforme as características da empresa, exames médicos e treinamentos (AMARILLA; IAROZINSKI NETO, 2018; IIDA, 2005).

O percentual da contribuição dos acidentes de trajeto tem aumentado ao longo do período pesquisado, atingindo o maior valor em 2014 para o Brasil de 16,16\% e 18,54\% em 2016 para o estado do Espírito Santo. A média dos últimos 12 anos dos acidentes de trajeto no ES e no Brasil é superior a 11\% com tendência de crescimento.

O percentual de acidentes de trajeto também tem apresentado crescimento em outros segmentos e em alguns municípios brasileiros o número de fatalidade de acidentes de trajeto é superior aos óbitos ocorridos em acidentes típicos (BERMUDES; BARROS, 2016; BRAGA, 2012; CORTEZ et al., 2017).

Almeida, Morrone e Ribeiro (2014) corroboram com esses dados ao descreverem em sua pesquisa a evolução do número de registros dos acidentes de trajeto quando comparara com os acidentes típicos, e apresenta a relação direta com o aumento da violência urbana no período de 1998 a 2008.

Lacerda, Fernandes e Nobre (2014) em sua análise identificaram no grupo pesquisado de um total de 91 acidentes fatais em Salvador - Bahia, envolvendo todos os tipos de 


\section{REVISTA LATINO-AMERICANA DE INOVAÇÃO E \\ ENGENHARIA DE PRODUÇÃO}

trabalhadores (públicos, privados e autônomos) 60,4\% foram ocorridos na execução de atividades laborais e 39,6\% de trajeto. Desses totais (91) 39,6\% foram ocorrência envolvendo o trânsito, $37,3 \%$ homicídios e $18,7 \%$ dentro do ambiente da empresa, reforçando a relevância dos agentes de riscos externo nos indicadores de acidentes.

Os riscos no deslocamento de casa para o trabalho e vice-versa, ou aqueles nas vias públicas a serviço da empresa, nem sempre ocorrem sob a gestão da proteção da empresa, pois os trabalhadores estão vulneráveis a ambientes externos como o trânsito, as estradas, violência urbana e outros (LACERDA; FERNANDES; NOBRE, 2014; SANTANA; NOBRE; WALDVOGEL, 2005).

Portanto a prevenção dos acidentes de trajeto não está limitada às ações dos setores de gestão de segurança e saúde do trabalho de uma organização, mas requer necessariamente o estabelecimento e aplicação de políticas de segurança pública, de segurança no trânsito, educação e até articulação com o judiciário. Fazem parte também para a redução desse índice a implementação de políticas de moradia, emprego, transporte e de renda, entre outras (OLIVEIRA; MENDES, 1997; SANTANA; NOBRE; WALDVOGEL, 2005).

\section{CONCLUSÕES}

Diante do exposto, concluiu-se que a apesar de um pequeno registro de acidentes de trabalho típico na construção de edifício no Espírito Santo quando comparado com o total de apontamento no Brasil, nota-se uma incidência maior no estado do que a média nacional. Percebe-se ainda uma tendência de redução de incidência de acidente no ES e no Brasil ao longo do período de 2007 a 2017. No que se refere a doença do trabalho, note-se também uma redução da incidência no Espírito Santo e no Brasil no período pesquisado.

O Estado do Espírito Santo, possui uma quantidade de registro de acidente que contribuiu em 5,48\% do total de acidentes no Brasil em 2008 e apresentou em 2017 o índice de $2,19 \%$, indicando queda dessa participação.

Os acidentes típicos e as doenças do trabalho são originados por diversos fatores com destaque para os trabalhos manuais, ausência de treinamentos, atitudes imprudentes, falta de utilização de equipamentos de proteção individual, uso de máquinas sem proteção e ausência de fiscalizações entre outros. 


\section{REVISTA LATINO-AMERICANA DE INOVAÇÃO E \\ ENGENHARIA DE PRODUÇÃO}

Para a redução dos acidentes destaca-se a aplicação de programa de prevenção de riscos adotados pelas empresas, atualização constante da norma regulamentadora 18 que prevê as condições mínimas de proteção ao trabalhador na construção civil, ações regressivas do Instituto Nacional do Seguro Social e o novo cálculo de Risco de Acidente de Trabalho.

Os acidentes de trajeto, ocorridos com os empregados da construção de edifícios tem uma contribuição média no período pesquisado de $11,80 \%$ no Brasil e $11,36 \%$ no estado do Espírito Santo. Esse indicador apresenta tendência de crescimento e registraram seu maior valor nesse segmento para o país em 2014 com 16,61\% e no Espírito Santo em 2016 com $18,54 \%$.

A redução dos índices de acidentes de trajeto passa por elaboração e aplicação de políticas governamentais que atuem na segurança pública, segurança no trânsito e educação, sendo necessário também ações que visam melhorar o transporte público, moradia, renda e transporte.

\section{REFERÊNCIAS}

AEAT - ANUÁRIO ESTATÍSTICO DE ACIDENTE DE TRABALHO 2017. Ministério da Fazenda ... [et al.]. - vol. 1 (2009) -. - Brasília: MF, 2017. 996 p.

ALMEIDA, F. S. e S de; MORRONE, L. C.; RIBEIRO, K. B. Tendências na incidência e mortalidade por acidentes de trabalho no Brasil, 1998 a 2008. Cadernos de Saúde Pública, v. 30, p. 1957-1964, 2014.

AMARILLA, R. S. D.; IAROZINSKI NETO, A. Análise comparativa dos principais processos de negócio de empresas do subsetor de edificações da construção civil. Gestão Produção, São Carlos, v. 25, n. 2, p. 269-283, Jun. 2018.

ANDERSEN, L. P. et al. Social identity, safety climate and self-reported accidents among construction workers. Construction Management and Economics, v. 36, n. 1, p. 22 31,2018 .

ASSUMPÇÃO, J. F. P.; LIMA JR, J. da R. Gerenciamento de empreendimentos na construção civil: modelo para planejamento estratégico da produção de edifícios. Escola Politécnica da Universidade de São Paulo Departamento de Engenharia de Construção Civil - Boletim Técnico. São Paulo: Escola Politécnica da Universidade de São Paulo - EPUSP, 1996. 
BERMUDES, W. L.; BARROS, E. V. de. Incidência de acidentes do trabalho de 2007 a 2013 em florestas plantadas nos estados brasileiros e os riscos dessa atividade. Revista Vértices. Campos dos Goytacazes/RJ, v.18, n.2, p. 53-64, maio/ago. 2016.

BEZERRA, I. X. B.; CARVALHO, R. J. M. de. Construção de um sistema de indicadores de desempenho em ergonomia na construção de edifícios: um modelo para alcançar a excelência no desempenho empresarial. Sistemas \& Gestão, v. 6, n. 3, p. 312-326, 2011.

BRAGA, C. S. Estudo de acidentes de trabalho no setor florestal. Universidade Federal de Viçosa - UFV. Dissertação de mestrado (Programa de Pós Graduação em Ciência Florestal). 86 f. 2012

BRASIL, Lei 8.213 - Dispõe sobre os Planos de Benefícios da Previdência Social e dá outras providências. 24 de julho de 1991 - Presidência da República. Disponível em $<$ http://www.planalto.gov.br/ccivil_03/leis/L8213cons.htm>. Acesso em: 27 jun. 2017.

CBIC - CÂMARA BRASILEIRA DA INDUSTRIA DA CONSTRUÇÃO, Relatório anualBanco de dados 2017. Disponível em < http://www.cbicdados.com.br/menu/pib-einvestimento/>. Acesso em: 27 jun 2018.

CORTEZ, E. A., et al. Análise da mortalidade por acidentes de trabalho no Brasil: revisão integrativa. Revista de enfermagem. Universidade Federal de Pernambuco - UFPE on line, p. 429-437, 2017.

FREITAS, A. J. de; et al. Qualidade de vida no trabalho e saúde e segurança ocupacional em uma organização da construção civil. Revista Gestão Organizacional, v. 9, n. 2, p. 423, 2016.

FREITAS, C. E. de; NISHIMURA, F.; ALMEIDA, R. Impacto do financiamento habitacional sobre o mercado de trabalho na construção civil. In: Anais do XLIV Encontro Nacional de Economia [ Proceedings of the 44th Brazilian Economics Meeting]. ANPEC-Associação Nacional dos Centros de Pós-Graduação em Economia [Brazilian Association of Graduate Programs in Economics], 2018.

IIDA, I. Ergonomia: projeto e produção. São Paulo: Edgard Blüncher, 2005.

LACERDA, K. M.; FERNANDES, R. de C. P.; NOBRE, L. C. da C. Acidentes de trabalho fatais em Salvador, BA: descrevendo o evento subnotificado e sua relação com a violência urbana. Rev. bras. saúde ocupacional, São Paulo, v. 39, n. 129, p. 63 74, jun. 2014.

LI, R. Y. M. Turning the Tide in the Construction Industry: From Traditional Construction Safety Measures to an Innovative Automated Approach. In: An Economic Analysis on Automated Construction Safety. Springer, Singapore, 2018. p. 1-22. 
MAIA, A. L. M. Análise preliminar de riscos em uma obra de construção civil. TECNOLOGIA \& INFORMAÇÃO - ISSN 2318-9622, v. 1, n. 3, p. 55-69, 2014.

MÜLLER, N. D. Levantamento de um embargo de obra, localizada na grande Florianópolis, SC e a adequação da mesma seguindo as recomendações da NR 18 e NR 35: construção civil. Monografia apresentada ao Curso de Especialização em Engenharia de Segurança do Trabalho da Universidade do Sul de Santa Catarina como requisito parcial à obtenção do título de Especialista em Engenharia de Segurança do Trabalho, 2018.

NININ, A. C. da S. Financiamento da previdência social no Brasil: recuperação de créditos através de ações regressivas acidentárias. Dissertação de Mestrado apresentado ao Programa de Pós Graduação em Economia da Faculdade de Ciências e Letras - Unesp de Araraquara, como requisito para obtenção do título de Mestre em Economia. 2018

OLIVEIRA, P. A. B.; MENDES, J. M. Acidentes de trabalho: violência urbana e morte em Porto Alegre, Rio Grande do Sul, Brasil. Cadernos de Saúde Pública, v. 13, p. S73S83, 1997.

REIS, M. B. dos; GUIMARÃES, G. M. Segurança do trabalho na construção civil: dados estatísticos de acidentes de trabalho e a prática da segurança do trabalho nos canteiros de obras. Trabalho de Conclusão de Curso apresentado ao Curso de Engenharia Civil da Universidade do Sul de Santa Catarina como requisito parcial à obtenção do título de Bacharel em Engenharia. 2017.

RONDON, D.; NÓBREGA, M. de J. R. da.; MAGDALENO, A. C. R. M. Estudo de acidentes de trabalho na construção de edifícios no Brasil. Revista Digital Simonsen Ano V, N ${ }^{\circ}$ 8., 2018.

SANTANA, V.; NOBRE, L.; WALDVOGEL, B. C. Acidentes de trabalho no Brasil entre 1994 e 2004: uma revisão. Ciência \& Saúde Coletiva, v. 10, p. 841-855, 2005.

SANTOS, A. M. dos; SOUSA, N. M. de; ARAUJO, A. P. D. Os riscos ambientais e o fator queda acometendo a saúde dos trabalhadores em canteiros de obra de edificação: Estudo de caso em Monteiro-PB. Revista Brasileira de Gestão Ambiental, v. 11, n. 1, p. 01-07, 2018.

SILVA, L. F. da. Gastos com acidentes de trabalho no Brasil: enfoque nos Riscos Ambientais do Trabalho-RAT e no Fator Acidentário de Prevenção - FAP. Trabalho de conclusão de curso ao departamento de ciências contábeis da Universidade Estadual da Paraíba. 2017.

SILVA, A. A. R da.; BEMFICA, G. do C. Segurança no trabalho na construção civil: uma revisão bibliográfica. Revista Pensar Engenharia, v. 1, n. 1, 2015. 
ZANETTE, J. et al. Análise do grau de conhecimento dos trabalhadores em segurança e medicina do trabalho em um edifício em construção na cidade de Chapecó/SC. Anais da Engenharia Civil - ISSN, v. 1, n. 1, p. 57-76, 2018.

VERGÍNIO, V. Risco de acidentes de trabalho e fator acidentário de prevenção-FAP: um estudo ecológico. UNIVERSIDADE DO SUL DE SANTA CATARINA - UNISUL. Trabalho de conclusão de curso Engenharia Segurança do Trabalho Florianópolis, 2018. 